\title{
Gender and ethnic differences in the post-liver transplant outcomes of patients with autoimmune hepatitis with acute liver failure at initial presentation: a case-control study
}

\author{
Paul J. Thuluvath ${ }^{1}$, Rebecca Rankin Wagennar², Sumita Verma ${ }^{3,4}$
}

\begin{abstract}
${ }^{1}$ Institute for Digestive and Liver Diseases, Mercy Medical Center, Baltimore, USA ${ }^{2}$ Virginia Mason Medical Center, Seattle, Washington, USA

${ }^{3}$ Department of Medicine, Brighton and Sussex Medical School, Brighton, UK ${ }^{4}$ Department of Gastroenterology and Hepatology, Brighton and Sussex Medical School, Brighton, UK
\end{abstract}

Submitted: 25 October 2014

Accepted: 5 November 2014

Arch Med Sci 2015; 11, 6: 1227-1235

DOI: 10.5114/aoms.2015.52736

Copyright (c) 2015 Termedia \& Banach

\author{
Corresponding author: \\ Paul J. Thuluvath MD, FRCP \\ Institute for Digestive Health \\ and Liver Diseases \\ Mercy Medical Center \\ Baltimore, MD 21202, USA \\ Georgetown University \\ School of Medicine \\ Washington, DC, USA \\ Phone: 4103329308 \\ Fax: 4106591178 \\ E-mail: thuluvath@gmail.com
}

\begin{abstract}
Introduction: Autoimmune hepatitis (AIH) may initially present as acute liver failure (ALF). The outcome of liver transplantation (LT) in patients with $\mathrm{AlH}$ and ALF is not very well defined. We determined the outcome of LT in UNOS (United Network for Organ Sharing) status 1 adult patients with and without AlH using post-MELD (Model for End-Stage Liver Disease) UNOS data.

Material and methods: For each $\mathrm{AlH}$ patient, 3 patients with non-AlH, matched for age \pm 5 years and donor risk index (DRI) \pm 5 years, were identified; 200 patients (50 AlH, 150 non-AlH) were found eligible for the study. Results: Patients with AlH were more likely to be female $(p=0.003)$, non-Caucasian $(p=0.009)$, have higher bilirubin $(p=0.003)$, longer waiting time $(p=0.01)$, and lower creatinine $(p=0.019)$. African American patients with AlH were younger $(p=0.003)$, had lower bilirubin $(p=0.037)$, and were more likely to have had a prior LT compared to Caucasians $(p=0.02)$. Kaplan-Meier analysis showed that 5-year post-LT survival was similar in those with and without AlH $(p=0.3)$. African American with AlH showed a trend for lower 5 -year survival compared to Caucasians ( $55 \%$ vs. $80 \%, p=N S$ ). Women had a better outcome, especially in those with non-AlH ( $p=0.002)$. Conclusions: Patients with AlH transplanted as status 1 have similar outcomes to those without AlH. Women with non-AlH-related ALF have better survival than their male counterparts.
\end{abstract}

Key words: autoimmune hepatitis, acute liver failure, liver transplantation.

\section{Introduction}

Autoimmune hepatitis (AlH) is a chronic inflammatory disorder of the liver characterized by a female preponderance, presence of autoantibodies, increased gamma globulins, and liver histology showing interface hepatitis that is predominantly lymphoplasmocytic [1]. While $\mathrm{AlH}$ can have protean manifestations, the majority of patients present with chronic or subclinical disease. In $10-25 \%$ of patients, however, the course can be more acute, with a fulminant presentation [2-4]. Acute liver failure (ALF), a serious clinical condition occurring in patients with no prior history of liver disease, is characterized by development of he- 
patic encephalopathy and coagulopathy [5], often resulting in multi-organ failure. In a survey in the US carried out between 1998 and 2008, AlH was found to be the underlying etiology in $5 \%$ of patients with ALF [6]. Similar data were reported from Europe, where $2-5 \%$ of patients with fulminant hepatic failure (FHF) had AlH as the underlying etiology $[7,8]$.

There is a paucity of published data in patients with fulminant onset of $\mathrm{AlH}$, and therefore their clinical characteristics, response to immunosuppression, and outcomes with and without liver transplantation (LT) remain poorly defined. Much of the controversy hinges on a critical management issue, i.e. whether such patients should be given a trial of corticosteroids, be priority listed for LT, or both. This is confounded by the variable response rates to corticosteroids (8-50\%) in patients with $\mathrm{AlH}$ who present with liver failure [3, $9,10]$. Furthermore, there are concerns whether initiating steroids in such ill patients could predispose them to an increased risk of infections without any additional benefits. Previous studies had suggested that patients transplanted for $\mathrm{AlH}$ have 5 -year survival in the range of 74-92\% [11-13]. These studies, however, had included mostly patients with chronic $\mathrm{AlH}$. There are only limited data available on the long-term post-LT outcomes of patients with $\mathrm{AlH}$ who were transplanted for fulminant disease. The aim of this study, therefore, was to assess 5-year patient survival of patients with AlH transplanted as UNOS status 1 (assuming that all adult patients who were transplanted as UNOS status 1 had presented with acute liver failure) and compare that to patients without $\mathrm{AlH}$, who were also transplanted as UNOS status 1 during the same time period.

\section{Material and methods}

Because of the heterogeneity of the patient population, we conducted a case-controlled study to adjust for some important confounders that may impact survival. For this study, we included only those adults ( $\geq 18$ years) who were transplanted as UNOS status 1 LT between 2002 and 2007, and hence all data were collected in the post-MELD era. We excluded those patients who were re-transplanted as status 1 for early graft failure after the initial liver transplantation [14]. For every patient with $\mathrm{AlH}(n=50)$, we selected three age ( \pm 5 years) and donor risk index (DRI) $( \pm 0.2$ points $)$ matched patients $(n=150)$ with non-AlH who were transplanted during the same period. The DRI was calculated, as previously described, using 3 variables that were shown to independently predict survival: donor age > 40 years, donation after cardiac death (DCD), and split/partial grafts [15].
The following data were recorded for recipients: age (in years), body mass index (BMI), ethnicity (Caucasian, African American (AA), Hispanic, Asian, and Others), patient status (alive or dead), serum bilirubin, creatinine and albumin, days on waiting list and number of prior LT. Donor characteristics recorded were age, BMI, ethnicity, gender, DRI, cold ischemic time (CIT), warm ischemic time (WIT), and serum creatinine.

The outcome variable of interest was patient survival in years. All subjects who were lost to follow-up or had not reached the primary endpoint of patient survival, defined as death, were censored and assumed to have the same underlying survival function as the non-censored subjects.

\section{Statistical analysis}

The data are presented as the mean \pm standard deviation (SD) or frequency followed by the relative frequency. Differences between continuous and categorical variables were analyzed by the Mann-Whitney and by Fisher's exact or $\chi^{2}$ test respectively. A 2-tailed $p$ value of less than 0.05 was considered significant. Kaplan-Meier survival analysis was performed to assess outcomes between the $\mathrm{AlH}$ and non-AlH groups, with the variable time of patient survival in years, where the end point of patient survival was defined as death. The differences between groups were assessed using a log-rank test. Cases with missing data for any particular measurement were omitted from analyses involving that variable. The statistical software used was SAS version 9.13 (Cary, NC, USA).

\section{Results}

Fifty patients with $\mathrm{AlH}$ were transplanted during the study period as status 1 . By study design, these 50 patients were compared to 150 patients with non-AlH. Table I compares the baseline demographic data in the AlH and non-AlH groups. Those with $\mathrm{AlH}$ were more likely to be female (80\% vs. $44.7 \%, p=0.0002$ ), have higher serum bilirubin $(p=0.003)$, and to have spent a longer time on the waiting list $(p=0.01)$ compared with their non-AlH counterparts. In contrast, the latter were more likely to be Caucasian (38\% vs. $64 \%$, $p=0.036)$, and have higher serum creatinine levels $(p=0.019)$. The BMI, MELD scores at time of listing, and number of previous LT were comparable in the two groups (Table I). There were no significant differences in donor characteristics between those with and without $\mathrm{AlH}$ as regards donor age, $\mathrm{BMI}$, gender, DRI, CIT, and WIT. Those in the AIH group, however, were more likely to receive a graft from a Hispanic donor $(p=0.04)$ (Table I).

Since AA were reported to have relatively worse outcomes compared to Caucasians, we compared 
Table I. Characteristics of patients with and without AlH and ALF

\begin{tabular}{|c|c|c|c|}
\hline Recipient factors & AlH $(N=50)$ & $\begin{array}{l}\text { Non-AlH } \\
N=150\end{array}$ & Value of $p$ \\
\hline Age & $44.0 \pm 14.3$ & $33.5 \pm 13.8$ & 0.68 \\
\hline BMI & $27.9 \pm 7.4$ & $26.8 \pm 6.2$ & 0.32 \\
\hline Ethnicity: & & & 0.009 \\
\hline White & $19(38)$ & $96(64)$ & 0.036 \\
\hline African American & $13(26)$ & $27(18)$ & 0.27 \\
\hline Hispanic & $11(22)$ & $20(13)$ & 0.18 \\
\hline Asian & $6(12)$ & $7(4.6)$ & 0.08 \\
\hline Other & $1(2)$ & 0 & 0.08 \\
\hline \multicolumn{4}{|l|}{ Gender: } \\
\hline Female & $40(80)$ & $67(44.7)$ & 0.003 \\
\hline Bilirubin & $20.7 \pm 13.5$ & $15.1 \pm 12.8$ & 0.003 \\
\hline Serum albumin at time of TX & $2.73 \pm 0.70$ & $2.65 \pm 0.70$ & 0.59 \\
\hline Days on wait list & $24.2 \pm 110.8$ & $14.6 \pm 65.5$ & 0.01 \\
\hline MELD & $30.3 \pm 8.1$ & $28 \pm 11.4$ & 0.59 \\
\hline Number of previous TX & $0.26 \pm 0.56$ & $0.38 \pm 0.51$ & 0.07 \\
\hline Creatinine & $1.5 \pm 1.5$ & $1.6 \pm 1.2$ & 0.019 \\
\hline \multicolumn{4}{|l|}{ Donor factors: } \\
\hline Age & $36.1 \pm 16.0$ & $38.7 \pm 17.9$ & 0.42 \\
\hline $\mathrm{BMI}$ & $24.9 \pm 4.2$ & $25.5 \pm 5.5$ & 0.71 \\
\hline Ethnicity: & & & 0.20 \\
\hline White & $32(64)$ & $115(76.7)$ & 0.37 \\
\hline African American & $5(10)$ & $16(10.7)$ & 0.90 \\
\hline Hispanic & $12(24)$ & $17(11.3)$ & 0.04 \\
\hline Asian & $1(2)$ & $1(0.67)$ & 0.41 \\
\hline Other & 0 & $1(0.67)$ & 0.56 \\
\hline Gender: & & & 0.39 \\
\hline Male & $30(60)$ & $100(66.7)$ & 0.61 \\
\hline Female & $20(40)$ & $50(33.3)$ & 0.49 \\
\hline DRI & $1.53 \pm 0.41$ & $1.53 \pm 0.40$ & 1.00 \\
\hline Cold ischemia time & $8.62 \pm 8.57$ & $7.38 \pm 3.64$ & 0.54 \\
\hline Warm ischemia time & $39.3 \pm 13.7$ & $34.8 \pm 13.1$ & 0.26 \\
\hline Creatinine & $1.32 \pm 2.87$ & $1.53 \pm 2.96$ & 0.15 \\
\hline \multicolumn{4}{|l|}{ Mortality: } \\
\hline Death & $13(26)$ & $58(38.7)$ & 0.78 \\
\hline
\end{tabular}

$B M I$ - Body mass index, TX - transplant, MELD - model for end stage liver disease, DRI - donor risk index.

the characteristics of these two groups (Table II). likely to have had a prior transplant in compariAfrican American were younger $(p=0.003)$, have son to the Caucasians $(p=0.025)$. There were no lower serum bilirubin $(p=0.037)$, but were more significant differences in donor characteristics, ex- 
Table II. Characteristics of African Americans and Caucasians with AlH and ALF

\begin{tabular}{|c|c|c|c|}
\hline Recipient factors & $\begin{array}{l}\text { African American } \\
\qquad(N=13)\end{array}$ & $\begin{array}{c}\text { Caucasian } \\
(N=19)\end{array}$ & Value of $p$ \\
\hline Age & $42.9 \pm 16.4$ & $50.4 \pm 10.4$ & 0.003 \\
\hline BMI & $26.0 \pm 5.1$ & $29.0 \pm 8.3$ & 0.95 \\
\hline Gender: & & & 0.78 \\
\hline Male & $4(30.8)$ & $5(26.3)$ & 0.37 \\
\hline Bilirubin & $15.8 \pm 8.6$ & $24.0 \pm 12.3$ & 0.037 \\
\hline Serum albumin at time of TX & $2.9 \pm 0.91$ & $2.6 \pm 0.72$ & 0.59 \\
\hline Days on wait list & $2.9 \pm 2.6$ & $4.6 \pm 3.1$ & 0.13 \\
\hline MELD & $30.7 \pm 6.6$ & $31.9 \pm 8.8$ & 0.86 \\
\hline Number of previous TX & $6(46)$ & $2(11)$ & 0.025 \\
\hline Creatinine & $2.1 \pm 1.6$ & $1.7 \pm 1.8$ & 0.36 \\
\hline \multicolumn{4}{|l|}{ Donor factors: } \\
\hline Age & $34.7 \pm 17.1$ & $33.00 \pm 16.90$ & 0.74 \\
\hline $\mathrm{BMI}$ & $26.2 \pm 4.3$ & $24.6 \pm 4.9$ & 0.41 \\
\hline Ethnicity: & & & 0.18 \\
\hline White & $11(84.6)$ & $12(63.1)$ & 0.28 \\
\hline African American & 0 & $3(15.8)$ & 0.56 \\
\hline Hispanic & $1(7.7)$ & $4(21.1)$ & 0.08 \\
\hline Asian & $1(7.7)$ & 0 & 0.23 \\
\hline Other & 0 & 0 & 1.00 \\
\hline Gender: & & & 0.22 \\
\hline Female & $4(30.8)$ & $10(52.6)$ & 0.020 \\
\hline DRI & $1.46 \pm 0.39$ & $1.56 \pm 0.46$ & 0.55 \\
\hline Cold ischemia time & $9.3 \pm 11.9$ & $7.6 \pm 2.8$ & 0.23 \\
\hline Warm ischemia time & $41.6 \pm 7.8$ & $40.5 \pm 10.8$ & 0.77 \\
\hline Creatinine & $0.83 \pm 0.28$ & $2.05 \pm 4.62$ & 0.43 \\
\hline \multicolumn{4}{|l|}{ Mortality: } \\
\hline Death & $5(38.5)$ & $4(21.1)$ & 0.83 \\
\hline
\end{tabular}

cept that the Caucasians were more likely to receive a graft from a female donor ( $p=0.02$ ) (Table II).

Table III compares gender differences in those with and without $\mathrm{AlH}$. Among the AlH group, no significant differences were observed both in the recipient and donor characteristics, except that females with $\mathrm{AlH}$ were more likely to have a female donor ( $p=0.0013)$. In those with non-AlH, men had a higher serum creatinine $(p=0.0002)$ and mortality $(p=0.019)$, but serum bilirubin was higher in the females $(p=0.02)$. In addition, men in the non-AlH group were more likely to receive a graft from a donor with a greater $\mathrm{BMI}$ $(p \leq 0.0001)$, and serum creatinine $(p=0.002)$, though with a shorter CIT $(p=0.028)$. Men with non-AlH had a higher mortality compared to women ( $49 \%$ vs. $25 \%, p=0.019$ ).

The 5-year survival was similar in those with and without AlH (Figure 1, $p=0.29$ ). The survival was similar in AA and Caucasians (Figure 2 A), but there was a lower survival in AA with AlH compared to Caucasians (65\% vs. $80 \%$ ), though the difference was not statistically significant (Figure $2 \mathrm{~B}$ ). Overall, women had a better outcome (Figure $3 \mathrm{~A}$, $p=0.002$ ). When stratified by disease, there were no gender differences in those with $\mathrm{AlH}$ (Figure 3 $\mathrm{B}, p=0.67$ ), but women with non-AlH had a significantly better survival compared to men (Figure $3 \mathrm{C}$, $p=0.004$ ).

\section{Discussion}

This case-controlled study showed that patients with AlH transplanted as UNOS status 1 were more likely to be female, non-Caucasian, and have higher serum bilirubin and longer waiting times, but lower serum creatinine compared to a non-AlH cohort. The 5-year survival, however, was similar in those with and without $\mathrm{AlH}$ transplanted as UNOS status 1 . AAs with $\mathrm{AlH}$ were 8 years younger than their Caucasian counterparts, and despite their younger age, showed a lower (though statistically non significant) 5-year surviv- 
Table III. Gender differences in those with and without AIH and ALF

\begin{tabular}{|c|c|c|c|c|c|c|}
\hline \multirow[t]{2}{*}{ Recipient factors } & \multicolumn{3}{|c|}{ AlH $(N=50)$} & \multicolumn{3}{|c|}{ Non-AIH $(N=150)$} \\
\hline & $\begin{array}{c}\text { Male } \\
(n=10)\end{array}$ & $\begin{array}{l}\text { Female } \\
(n=40)\end{array}$ & Value of $p$ & $\begin{array}{c}\text { Male } \\
(n=83)\end{array}$ & $\begin{array}{l}\text { Female } \\
(n=67)\end{array}$ & Value of $p$ \\
\hline Age & $43.7 \pm 16.5$ & $44.1 \pm 14.0$ & 1.00 & $45.0 \pm 13.1$ & $41.6 \pm 14.6$ & 0.17 \\
\hline BMI & $27.1 \pm 10.3$ & $28.2 \pm 6.6$ & 0.27 & $26.9 \pm 5.6$ & $25.9 \pm 6.8$ & 0.066 \\
\hline Ethnicity: & & & 0.41 & & & 0.83 \\
\hline White & 5 & 14 & 0.49 & 53 & 43 & 0.98 \\
\hline African American & 4 & 9 & 0.33 & 14 & 13 & 0.71 \\
\hline Hispanic & 1 & 10 & 0.37 & 11 & 9 & 0.97 \\
\hline Asian & 0 & 6 & 0.96 & 5 & 2 & 0.39 \\
\hline Other & 0 & 1 & 0.62 & 0 & 0 & 1.00 \\
\hline Bilirubin & $19.53 \pm 10.20$ & $21.02 \pm 14.35$ & 1.00 & $13.20 \pm 12.68$ & $17.56 \pm 12.62$ & 0.019 \\
\hline Serum albumin at time of $\mathrm{TX}$ & $2.72 \pm 1.04$ & $2.74 \pm 0.60$ & 0.65 & $2.64 \pm 0.82$ & $2.67 \pm 0.52$ & 0.72 \\
\hline Days on wait list & $3.0 \pm 1.9$ & $29.6 \pm 123.5$ & 0.11 & $23.9 \pm 87.2$ & $3.0 \pm 3.4$ & 0.14 \\
\hline MELD & $32.8 \pm 7.9$ & $29.7 \pm 8.1$ & 0.20 & $29.1 \pm 12.9$ & $28.2 \pm 9.3$ & 0.46 \\
\hline Number of previous TX & $0.6 \pm 1.0$ & $0.2 \pm 0.4$ & 0.11 & $0.39 \pm 0.54$ & $0.37 \pm 0.49$ & 0.97 \\
\hline Creatinine & $1.85 \pm 1.12$ & $1.39 \pm 1.56$ & 0.07 & $1.90 \pm 1.34$ & $1.24 \pm 0.82$ & 0.0002 \\
\hline Donor factors & Male & Female & Value of $p$ & Male & Female & Value of $p$ \\
\hline Age & $31.5 \pm 15.6$ & $37.2 \pm 16.1$ & 0.30 & $37.45 \pm 18.16$ & $40.31 \pm 17.63$ & 0.34 \\
\hline BMI & $26.1 \pm 5.7$ & $24.6 \pm 3.8$ & 0.61 & $27.1 \pm 5.9$ & $23.6 \pm 4.3$ & $<0.0001$ \\
\hline Ethnicity: & & & 0.62 & & & 0.23 \\
\hline White & 7 & 25 & 0.79 & 62 & 53 & 0.76 \\
\hline African American & 0 & 5 & 0.0013 & 12 & 4 & 0.11 \\
\hline Hispanic & 3 & 9 & 0.67 & 7 & 10 & 0.24 \\
\hline Asian & 0 & 1 & 0.62 & 1 & 0 & 0.37 \\
\hline Other & 0 & 0 & 1.00 & 1 & 0 & 0.37 \\
\hline Gender: & & & 0.15 & & & 0.048 \\
\hline Female & 6 & 14 & 0.26 & 22 & 28 & 0.11 \\
\hline DRI & $1.40 \pm 0.36$ & $1.56 \pm 8.15$ & 0.27 & $1.57 \pm 0.41$ & $1.50 \pm 0.38$ & 0.30 \\
\hline Cold ischemia time & $6.19 \pm 2.14$ & $9.18 \pm 9.38$ & 0.43 & $7.77 \pm 3.49$ & $6.95 \pm 3.78$ & 0.028 \\
\hline Warm ischemia time & $37.86 \pm 6.54$ & $39.62 \pm 14.81$ & 0.98 & $35.43 \pm 13.77$ & $34.09 \pm 12.40$ & 0.43 \\
\hline Creatinine & $0.82 \pm 0.41$ & $1.45 \pm 3.20$ & 0.40 & $1.17 \pm 0.57$ & $1.98 \pm 4.35$ & 0.002 \\
\hline \multicolumn{7}{|l|}{ Mortality: } \\
\hline Death & 3 & 10 & 0.78 & 41 & 17 & 0.019 \\
\hline
\end{tabular}

al compared to Caucasians. Additionally, women, especially those in the non-AlH group, had significantly better survival compared to men.

Acute liver failure accounts for $6 \%$ to $7 \%$ of all LT in the United States and $11 \%$ in Europe [16, 17]. In the pre-transplantation era, survival of pa- tients who presented with ALF was only 6-22\% $[18,19]$. Recent data from the European Liver Transplant Registry suggest that there has been significant improvement in survival among patients transplanted for ALF with 1-, 5- and 10-year patient and graft survival rates of $74 \%, 68 \%, 63 \%$, 


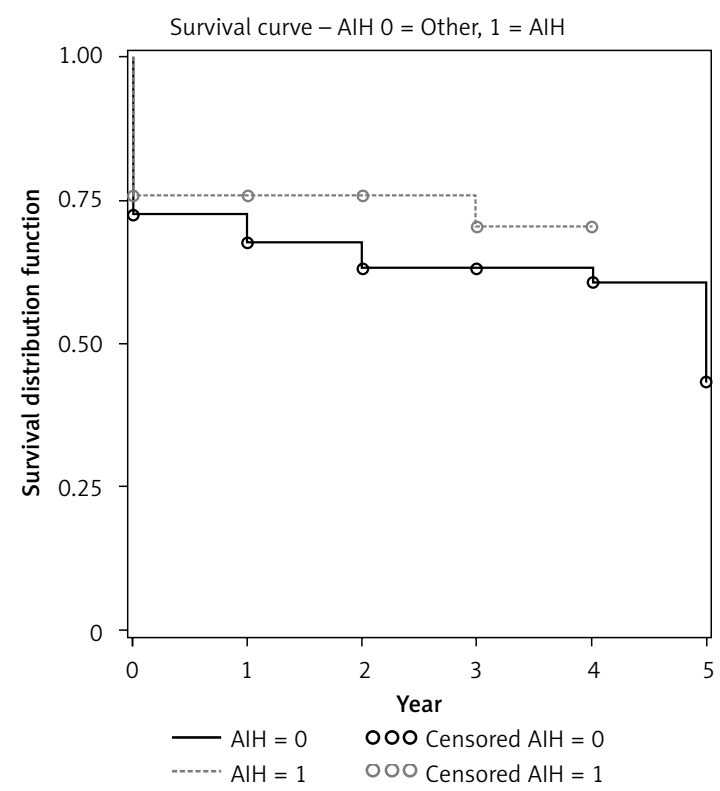

Figure 1. Kaplan-Meier survival curves in UNOS status 1 patients with AlH and non-AlH (log rank $\chi^{2}$ test $=1.10, p=0.29$ )

and $63 \%, 57 \%, 50 \%$ respectively [20]. In fact in Europe, the 10-year survival gap between patients transplanted for ALF versus chronic liver disease has decreased from $15 \%$ to $5 \%$ [16]. Similarly, results from the US Acute Liver Failure Study Group indicate excellent 3-year survival in ALF (82\%) over the last decade [21]. Factors predictive of poor outcome after LT for ALF are donor BMI > 30 $\mathrm{kg} / \mathrm{m}^{2}$, non-Caucasian ethnicity, serum creatinine $>2 \mathrm{mg} / \mathrm{dl}$, recipient age $>50$ years, donor age $>60$

A

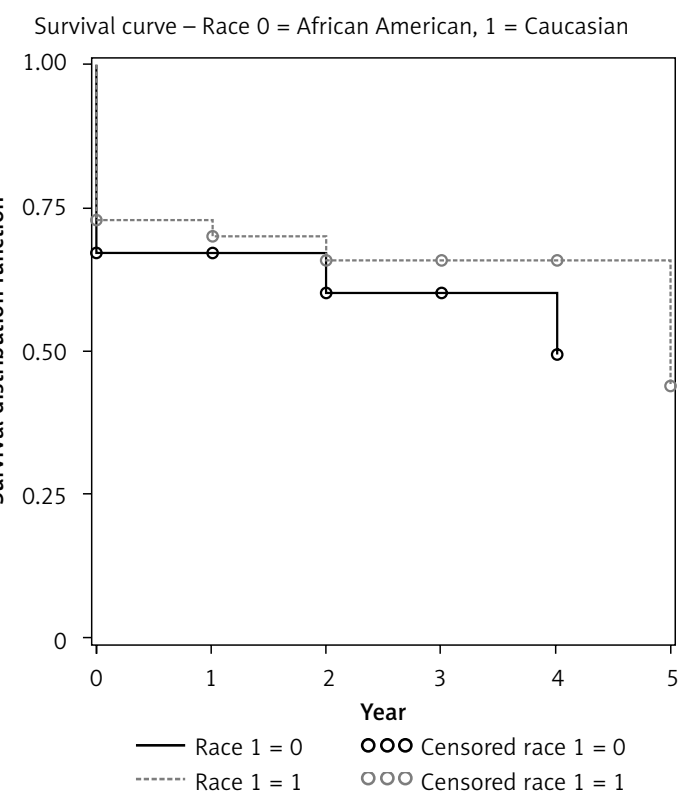

years, history of life support and non-viral etiology of the ALF [21-23].

Previous studies had reported that overall patient/graft survival in patients with $\mathrm{AlH}$ at 1 year (97.5\%/97.5\%), 2 years (93\%/91.2\%) and 5 years (93\%/87\%) is excellent, but the majority of these patients presented with chronic liver failure [12]. There are only limited data on patients with $\mathrm{AlH}$ and a fulminant presentation. A small Spanish study reported better survival for patients with $\mathrm{AlH}$ and $\operatorname{ALF}(n=7)$ at 1 and 5 years compared to those with chronic AlH $(n=8)$ [24]. The 5-year post-LT survival of $62.5 \%$ in patients with $\mathrm{AlH}$ and ALF in their study corroborates our data, as our 5 -year survival in this cohort was just over $60 \%$. In another study where just over a third had ALF due to $\mathrm{AlH}$, with the others having chronic $\mathrm{AlH}$, after a median follow-up period of 530 days, the overall patient and graft survival rates were $>90 \%$ [25].

Bacterial and fungal sepsis are responsible for almost one third of deaths after LT for ALF and in conjunction with multisystem failure are the most common cause of death $[20,22,26,27]$. Because patients with AlH are likely to be on corticosteroids before the transplant, there is a perception that they may be at increased risk of sepsis-related morbidity and mortality. In this study, data on corticosteroid use and subsequent development of sepsis were not available. We have previously shown that in patients with $\mathrm{AlH}$ and initial presentation with liver failure, a lower MELD score at admission ( $\leq 28)$, more severe hepatic fibrosis, and an early (within 4 days of steroid therapy) im-

\section{B}

Survival curve $(\mathrm{AlH})-$ Race 0 = African American, 1 = Caucasian

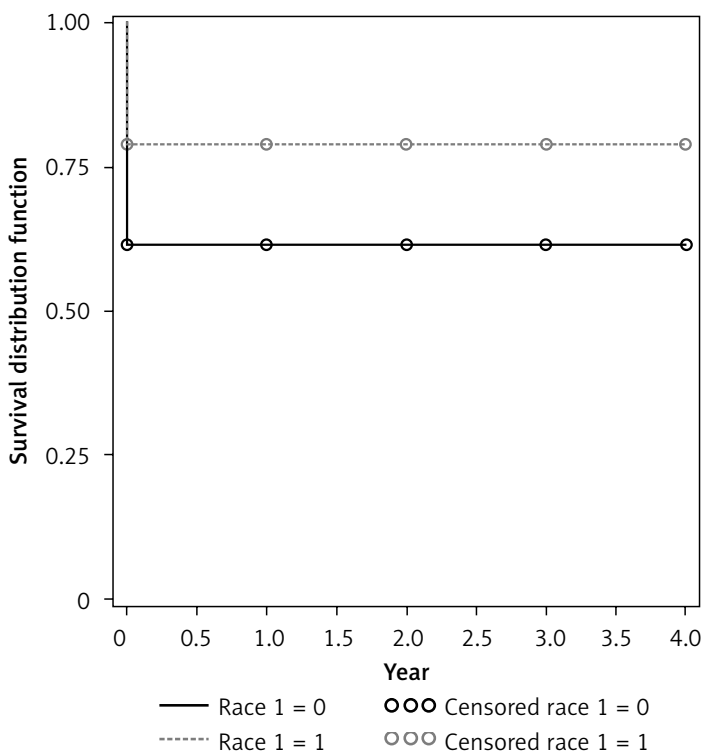

Figure 2. A - Kaplan-Meier survival curves of UNOS status 1 patients (overall) stratified by ethnicity (AA vs. Caucasian; log rank $\chi^{2}=1.17, p=0.28$ ); B - Kaplan-Meier survival curves of UNOS status 1 patients with AlH, stratified by ethnicity (AA vs. Caucasian; log rank $\chi^{2}=1.12, p=0.29$ ) 
A

Survival curve - Gender $0=$ male, $1=$ female

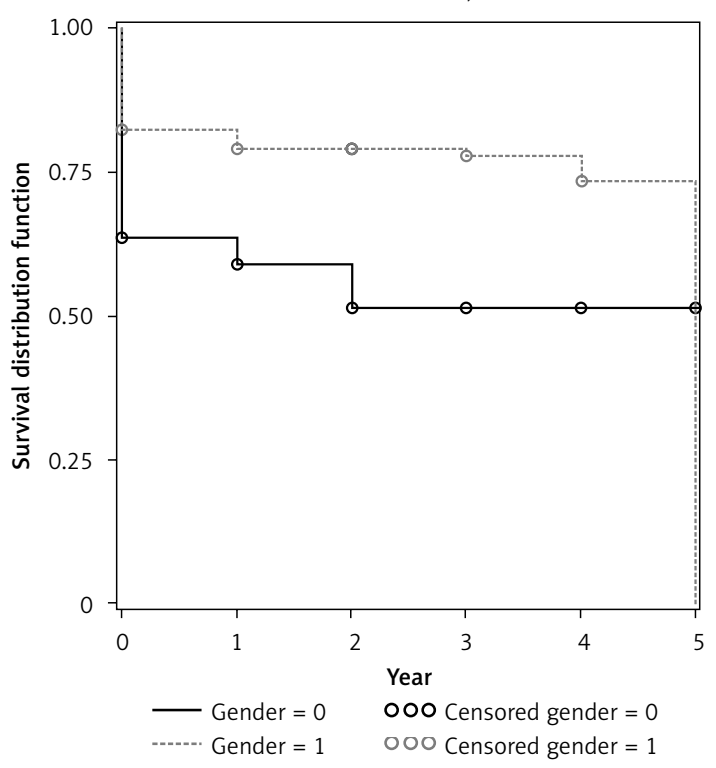

C

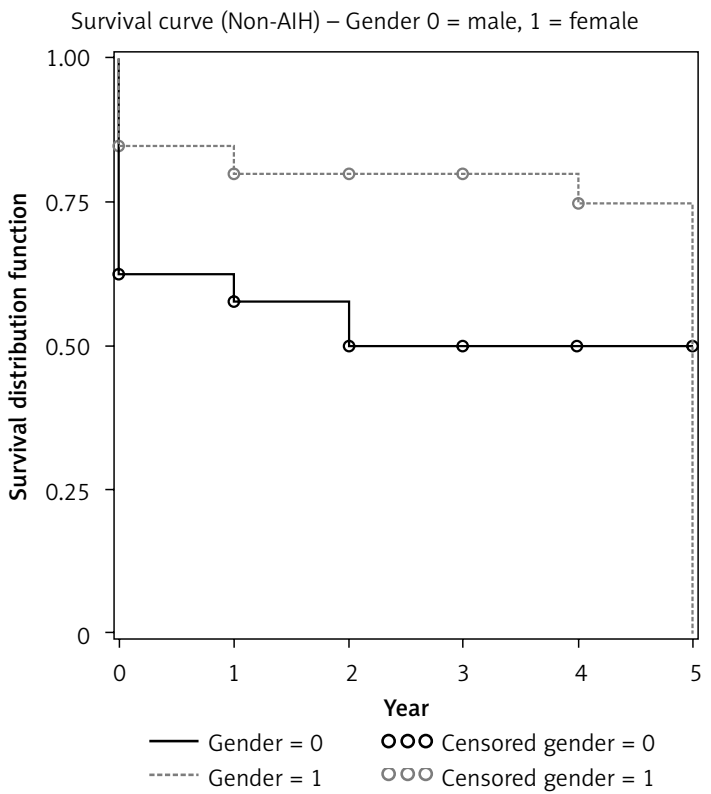

provement or stabilization in serum bilirubin and INR, identified those who were likely to respond to corticosteroid therapy, and thereby survive without LT [28]. Such an early stratification strategy could optimize care of patients with $\mathrm{AlH}$ who present with liver failure, and avoid unnecessary treatment with corticosteroids. In the current study, 5-year survival was no different in those with and without $\mathrm{AlH}$, and hence we can speculate that even if corticosteroid usage was associated with increased risk of infections, it did not appear to impact the longterm survival of those with AlH and ALF.

Other factors that may be associated with poorer post-LT outcomes in those with AlH included a higher risk of acute cellular rejection
B

Survival curve $(\mathrm{AlH})-$ Gender $0=$ male, $1=$ female

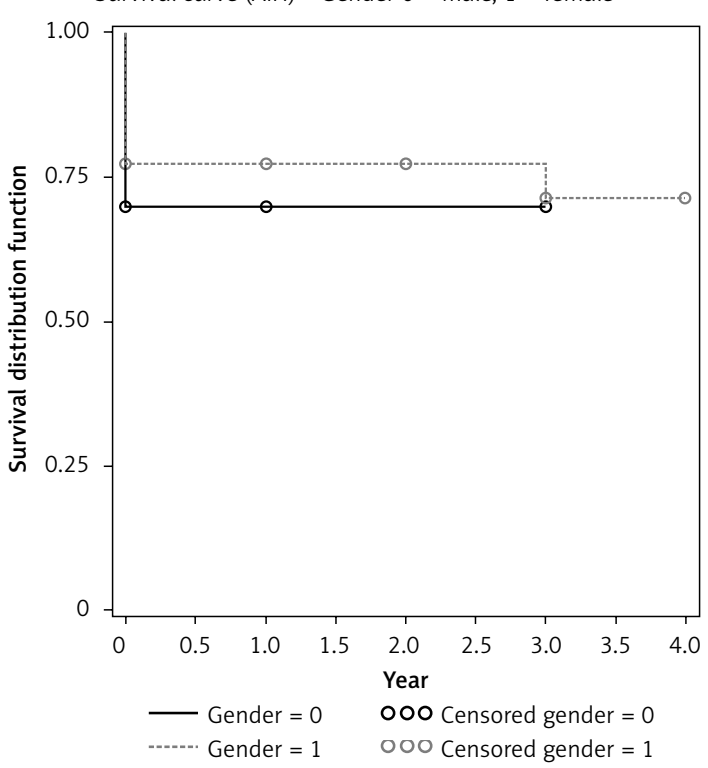

Figure 3. A - Kaplan-Meier survival curves in UNOS status 1 patients (overall) stratified by gender (male vs. female; log rank $\chi^{2}=9.43, p=0.002$ ); B - Kaplan-Meier survival curves of UNOS status 1 patients with AlH stratified by gender (male vs. female; log rank $\chi^{2}=0.18, p=0.67$ ); $C$ - Kaplan-Meier survival curves of UNOS status 1 patients without $\mathrm{AlH}$, stratified by gender (male vs. female; log rank $\chi^{2}=8.18, p=0.004$ )

(reported incidence between $75 \%$ and $83 \%$ ) and possibly disease recurrence in the graft $[2,12,29]$. European studies have suggested that there is a progressive increase in $\mathrm{AlH}$ recurrence, reaching more than $60 \%$ after 5 years of follow-up [30, 31]. Because of the retrospective nature of our study, we did not have access to data on incidence of rejection and disease recurrence. Núñez-Martínez et al., however, reported no differences between ALF and chronic AlH patients as regards acute and chronic rejection episodes, and biliary and arterial graft complications [24].

A review of the UNOS database from 19882004 found that $\mathrm{AlH}$ was more frequently found amongst blacks [32]. This is consistent with our 
data, and in our study only $38 \%$ of those in the AlH group were Caucasians compared to $64 \%$ in the non-AlH group ( $p=0.036)$. This over-representation of non-Caucasians in those with $\mathrm{AlH}$ may be related to more aggressive disease in this ethnic group. We in fact had previously reported that at presentation, black patients with AlH were more likely to have cirrhosis $(56.7 \%$ vs. $37.5 \%$, $p=0.061)$, liver failure (37.8\% vs. $9.3 \%, p=0.001)$, be referred for LT $(51.3 \%$ vs. $23.4 \%, p=0.004)$, and consequently have higher mortality $(24.3 \%$ vs. $6.2 \%, p=0.009$ ) [28]. In this study, although not statistically significant perhaps because of the smaller sample size, the survival curves in those with $\mathrm{AlH}$ showed a lower (though statistically non significant) 5 -year survival in AA compared to Caucasians (65\% vs. $80 \%$ ). Furthermore, another recent study found significantly lower 2-year graft survival (68\% vs. $74 \%$ ) and 2-year and 5 -year patient survival (74\% and $48 \%$ and $83 \%$ and $58 \%$, respectively) in AA compared to White Americans [33]. In addition to a propensity towards more aggressive disease, another factor contributing to the lower post-LT survival in AA could be the higher incidence of chronic rejection in AA compared to White Americans (12\% vs. $6 \%$ ) [34]. We in fact observed that AAs with AlH were more likely to have had a prior LT ( $46 \%$ vs. $11 \%$, $p=0.025)$, as has been reported by others [34]. Whether this is related to more severe disease at onset [28], racial differences in pharmacokinetics of immunosuppressants [34], pharmacogenomics or non-compliance remains uncertain. Since this was a retrospective study, data on corticosteroid usage and corticosteroid-related septic events, the incidence of graft loss due to acute/chronic rejection and disease recurrence were unavailable. These are some of the inherent limitations of the UNOS database.

An interesting observation in our study was the significantly better survival in women, especially those in the non-AlH group listed as UNOS status 1 . This may have been related to greater BMI and serum creatinine at the time of listing in men, as well as receiving a graft from a heavier donor. These factors have been associated with poorer outcomes after LT for ALF in prior studies [22].

In conclusion, patients with and without $\mathrm{AlH}$, listed as UNOS status 1 , seem to have similar 5-year survival after LT, but in those with $\mathrm{AlH}$, there was a lower (statistically non significant) survival in AA compared to Caucasians. Further prospective studies are needed to address this issue.

\section{Conflict of interest}

The authors declare no conflict of interest.

\section{References}

1. Manns MP, Czaja AJ, Gorham JD, et al.; American Association for the Study of Liver Disease. Diagnosis and management of autoimmune hepatitis. Hepatology 2010; 51: 2193-213.

2. Reich DJ, Fiel I, Guarrera JV, et al. Liver transplantation for autoimmune hepatitis. Hepatology 2000; 32: 693-700.

3. Verma S, Maheshwari A, Thuluvath PJ. Liver failure as initial presentation of autoimmune hepatitis: clinical characteristics, predictors of response to steroid therapy and outcomes. Hepatology 2009; 49: 1396-7.

4. Miyake Y, Iwasaki Y, Terada R, et al. Clinical characteristics of fulminant-type autoimmune hepatitis: an analysis of eleven cases. Aliment Pharmacol Ther 2006; 23: 1347-53.

5. O'Grady JG, Schalm SW, Williams R. Acute liver failure: redefining the syndromes. Lancet 1993; 343: 273-5.

6. Lee WM, Squires RH Jr, Nyberg SL, Doo E, Hoofnagle JH. Acute liver failure: summary of a workshop. Hepatology 2008; 47: 1401-15.

7. Escorsell A, Mas A, de la Mata M; Spanish Group for the Study of Acute Liver Failure. Acute liver failure in Spain: analysis of 267 cases. Liver Transpl 2007; 13: 1389-95.

8. Brandsaeter B, Höckerstedt K, Friman S, et al. Fulminant hepatic failure: outcome after listing for highly urgent liver transplantation-12 years experience in the nordic countries. Liver Transpl 2002; 8: 1055-69.

9. Ichai P, Duclos-Vallee JC, Guettier C, et al. Usefulness of corticosteroids for the treatment of severe and fulminant forms of autoimmune hepatitis. Liver Transpl 2007; 13: 996-1003.

10. Villamil AG, Casciato P, Eduardo M, et al. Fulminant autoimmune hepatitis type 1: clinical presentation, outcome and prognostic factors. Am J Transpl 2005; 5 (Suppl. 11): 278.

11. Ratziu V, Samuel D, Sebagh M, et al. Long-term follow-up after liver transplantation for autoimmune hepatitis: evidence of recurrence of primary disease. J Hepatol 1999; 30: 131-41.

12. Narumi S, Hakamada K, Sasaki M, et al. Liver transplantation for autoimmune hepatitis: rejection and recurrence. Transplant Proc 1999; 31: 1955-6.

13. Campsen J, Zimmerman MA, Trotter JF, et al. Liver transplantation for autoimmune hepatitis and the success of aggressive corticosteroid withdrawal. Liver Transpl 2008; 14: 1281-6.

14. United Network for Organ Sharing. Policy 3.6. Allocation of livers. Available at: http://www.optn.org/organDatasource/OrganSpecificPolicies.asp?display_Liver. Accessed 14th February, 2009.

15. Feng S, Goodrich NP, Bragg-Gresham JL, et al. Characteristics associated with liver graft failure: the concept of a donor risk index. Am J Transplant 2006; 6: 783-90.

16. European Transplant Registry. Available at: http://www. eltr.org. Accessed February 14th 2009.

17. Freeman RB Jr, Steffick DE, Guidinger MK, Farmer DG, Berg CL, Merion RM. Liver and intestine transplantation in the United States, 1997-2006. Am J Transplant 2008; 8: 958-76.

18. Rakela J, Lange SM, Ludwig J, Baldus WP. Fulminant hepatitis: Mayo Clinic experience with 34 cases. Mayo Clin Proc 1985; 60: 289-92.

19. Rakela J, Mosley JW, Edwards VM, Govindarajan S, Alpert E. A double-blinded, randomized trial of hydrocortisone in acute hepatic failure. The Acute Hepatic Failure Study Group. Dig Dis Sci 1991; 36: 1223-8.

20. Germani G, Theocharidou E, Adam R, et al. Liver transplantation for acute liver failure in Europe: outcomes 
over 20 years from the ELTR database. J Hepatol 2012; 57: 288-96.

21. Reddy KR, Schilsky ML, Stravitz R, et al. Liver transplan tation (LT) for acute liver failure (ALF): results from the NIH Acute Liver Failure Study Group (ALFSG). Hepatology 2012; 56: 247A.

22. Barshes NR, Lee TC, Balkrishnan R, Karpen SJ, Carter BA, Goss JA. Risk stratification of adult patients undergoing orthotopic liver transplantation for fulminant hepatic failure. Transplantation 2006; 81: 195-201.

23. Devlin J, Wendon J, Heaton N, Tan KC, Williams R. Pretransplantation clinical status and outcome of emergency transplantation for acute liver failure. Hepatology 1995; 21: 1018-24.

24. Núñez-Martínez O, De la Cruz G, Salcedo M, et al. Liver transplantation for autoimmune hepatitis: fulminant versus chronic hepatitis presentation. Transplant Proc 2003; 35: 1857-8.

25. Khalaf H, Mourad W, El-Sheikh Y, et al. Liver transplantation for autoimmune hepatitis: a single-center experience. Transpl Proc 2007; 39: 1166-70.

26. Karvellas CJ, Pink F, McPhail M, et al. Predictors of bacteremia and mortality in patients with acute liver failure. Intensive Care Med 2009; 35: 1390-6.

27. Czaja A. Corticosteroids or not in severe acute or fulminant autoimmune hepatitis: therapeutic brinksmanship and the point beyond salvation. Liver Transpl 2007; 13: 996-1003.

28. Verma S, Torbenson M, Thuluvath PJ. The impact of ethnicity on the natural history of autoimmune hepatitis. Hepatology 2007; 46: 1828-35.

29. Czaja AJ. Diagnosis, pathogenesis, and treatment of autoimmune hepatitis after liver transplantation. Dig Dis Sci 2012; 57: 2248-66.

30. Prados E, Cuervas-Mons V, de la Mata M, et al. Outcome of autoimmune hepatitis after liver transplantation. Transplantation 1998; 66: 1645-50.

31. Duclos-Vallee JC, Sebagh M, Rifai K, et al. A 10 year follow up study of patients transplanted for autoimmune hepatitis: histological recurrence precedes clinical and biochemical recurrence. Gut 2003; 52: 893-7.

32. Futagawa Y, Terasaki PI. An analysis of the OPTN/UNOS Liver Transplant Registry. Clin Transpl 2004; 18: 315-29.

33. Satheesh N, Eustace J, Thuluvath PJ. Effect of race on outcome of orthotopic liver transplantation: a cohort study. Lancet 2002; 359: 287-93.

34. Zolfino T, Heneghan MA, Norris S, Harrison PM, Portmann BC, McFarlane IG. Characteristics of autoimmune hepatitis in patients who are not of European Caucasoid ethnic origin. Gut 2002; 50: 713-7. 